\title{
Democracia, sanción penal y consentimiento: consideraciones generales acerca del papel del consentimiento en un sistema penal (¿ideal?)
}

\author{
Democracy, Punishment and Consent: Ceneral Remarks on the Role \\ of Consent in a(n) (Ideal?) Criminal System
}

\author{
Matías PARMigiani \\ Universidad Nacional de Córdoba \\ https://orcid.org/0000-0002-5462-5781 \\ matias_parmigiani@yahoo.com.ar
}

RECIBIDO: 12/03/2019/ACEPTADO: 01/11/2019

\begin{abstract}
Resumen: Todo sistema penal actúa alterando los mecanismos motivacionales que explican la conducta de los individuos. En esa tarea, el rol del dispositivo sancionatorio parece crucial. Según una suposición estándar, ligada al utilitarismo, si aumenta la eficacia sancionatoria, proporcionalmente tenderá a aumentar el grado de acatamiento normativo. Sin embargo, en el presente trabajo no sólo intento mostrar que la correlación existente entre estos dos factores es más compleja de lo que admite aquella suposición, sino también que una comprensión más ambiciosa de las motivaciones humanas arroja una serie de inferencias sobre la legitimidad y justicia de los sistemas penales que impactan de lleno en su justificación moral. A partir de un conjunto de postulados acerca del modo en que los sistemas penales garantizarían las precondiciones de la democracia (deliberativa), el fin último que aquí persigo es el de diseñar un modelo evaluativo integral de los mismos que descanse en la noción de consentimiento.
\end{abstract}

Palabras clave: democracia ddeliberativa; sistema penal; legitimidad; justicia; razones para la acción; Nino; utilitarismo; retribucionismo; consentimiento.

\begin{abstract}
Criminal systems operate by altering the motivational mechanisms that explain individuals' behavior. To do that, the sanctioning device seems to play a major role. According to a standardly utilitarian assumption, an increment in sanction efficacy is usually followed by a proportional increment in normative compliance. In the present paper, however, I will try to show not only that the correlation between these two factors is more complex than the assumption admits, but also that a deeper understanding of human motivations provides greater insight into some aspects of our criminal systems' justice and legitimacy that may have an impact on their moral justification. Arguing from a set of postulates that conceive our criminal systems as guaranteeing the preconditions of (deliberative) democracy, my ultimate aim will be to design a comprehensive evaluative model of the way they function grounded on the notion of consent.
\end{abstract}

Keywords: deliberative democracy; criminal system; legitimacy; justice; reasons for action; Nino; utilitarianism; retributivism; consent.

SUmario: 1. DEMOCRACIA Y SISTEMA PENAL: DE PRECONDICIONES Y POSTULADOS. 2. CONSENTIMIENTO, MOTIVACIÓN Y SISTEMAS PENALES: UNA PROPUESTA EVALUATIVA. 2.1. La obediencia al sistema. 2.2. La legitimidad del sistema. 2.3. La justicia del sistema. 2.4. La desobediencia al (y los límites motivacionales del) sistema. 2.5. Derivaciones. 3. EL CONSENTIMIENTO A LA SANCIÓN Y LOS LÍMITES DE LA DEMOCRACIA. BIBLIOGRAFÍA.

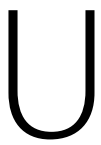

n sistema de justicia penal actúa alterando los mecanismos motivacionales que explican la conducta de los individuos. Trátese de un sistema penal justo o injusto, legítimo o ilegítimo, dictatorial o democrático, completo o incompleto, válido o inválido, eficaz o ineficaz, su modus operandi 
tiende a ser casi siempre el mismo. No importa cuán justas o variadas sean sus leyes, a cuánto asciendan las instancias procesales que intervienen antes de cada condena, o cuán intrusivos sean los mecanismos de vigilancia dispuestos para atrapar a los infractores. Todo sistema penal actúa comunicando a sus destinatarios una especie de mensaje, que cada cual interpretará como pueda, a la luz de los recursos intelectuales o materiales de los que disponga, para finalmente adecuar sus preferencias, motivaciones o intereses a las conductas que juzgue más apropiadas o convenientes.

En este punto, no parece haber mayores desacuerdos. Visto en abstracto, el problema de la justificación del castigo nunca fue -hasta donde entiendoun problema relativo al modo como operan los sistemas penales desde el punto de vista psicológico. Fue más bien un problema auténticamente moral, relativo a la validez, legitimidad o justicia de contar con un dispositivo que justamente actúe ejerciendo esta influencia psicológica sobre los individuos, la cual -al menos desde cierto punto de vista- indudablemente vendría a restringir nuestras libertades personales. Por cierto, también fue un problema moral relativo a la validez, legitimidad o justicia de contar con un dispositivo que ejerza esta influencia psicológica apelando en última instancia a una medida que distribuye sobre cada (presunto) infractor una determinada dosis de sufrimiento, privándolo de ciertos derechos moralmente reconocidos.

Ahora bien, aunque el problema de la justificación del castigo nunca haya sido un problema psicológico, resulta indudable que ciertas características que cualquier teoría estimaría importantes en un sistema penal, tales como su grado de eficacia sancionatoria o su nivel de acatamiento normativo, están causalmente vinculadas a los mecanismos motivacionales con los que opera. Según podríamos aventurar, casi ninguna de las teorías justificatorias más tradicionales que se han esgrimido a favor de la pena, como el utilitarismo o el retribucionismo, ha osado poner en cuestión este hecho. Sin embargo, bien podría suceder que algunos supuestos o principios en los que ellas se apoyan, al ser evaluados a la luz del comportamiento de tales mecanismos motivacionales, se revelaran en la práctica carentes de fundamento. Justamente, uno de los objetivos que aquí persigo consiste en demostrar que ni la simple disuasión o prevención del delito (o la protección de ciertos bienes; Braithwaite y Pettit, que se reconocen consecuencialistas, hablan de la necesidad de garantizar el auto-dominio) (cfr. Braithwaite y Pettit 2015, cap. 4), históricamente asociada a la justificación utilitarista de la pena, ni tampoco la función expresiva o comunicativa que ella cumpliría según ciertos enfoques contemporáneas posiblemente emparentados al retribucionismo (cfr. Wood 2002, p. 302), resultan 
completamente satisfactorias para explicar en toda su dimensión el funcionamiento y la finalidad de un sistema penal.

¿Qué sucede cuando un sistema penal falla en alterar los mecanismos motivacionales de sus destinatarios? Una respuesta a todas luces inadecuada sería decir que falla en prevenir el delito, pues perfectamente podría ser el caso que no se constatara ningún tipo delito, pero que ello obedeciera a una influencia motivacional proveniente de otras clases de dispositivos o factores, sean de índole social, institucional o netamente individual. Por ejemplo, un sistema penal que fuera muy benevolente, aunque absolutamente eficaz, podría no ser en modo alguno suficiente para prevenir por sí mismo cierto tipo de delitos. Sin embargo, sí podría serlo en caso de operar en el seno de una comunidad y de un sistema social que distribuyera otra clase de incentivos, como los que se manifiestan en algunas prácticas más informales de reconocimiento o reproche. Ahora bien, si hay algo que revela esta respuesta es justamente la incomodidad de la pregunta inicial. En lugar de preguntarnos qué sucede cuando un sistema penal falla en alterar los mecanismos motivacionales de sus destinatarios, lo que más bien debemos preguntarnos es qué nos permite inferir $e l$ becho de que en una sociedad se constaten un determinado número de delitos acerca del comportamiento de un sistema penal.

En este punto cabría introducir una distinción importante. Un sistema penal que no alcanza a proteger ciertos bienes no necesariamente se trata de un sistema penal afectado por una deficiencia motivacional. Se trataría de un sistema semejante, en efecto, si las leyes que lo presiden tipificaran ciertas conductas como delitos. Pero no siendo así, tan sólo podría tratarse, como veremos a continuación, de un sistema penal injusto. Ahora, suponiendo que sí se constate dicha tipificación legal y ciertas conductas tipificadas se produzcan, la falla o deficiencia motivacional del sistema parecerá evidente. ¿Lo es? En este trabajo no sólo intento demostrar que no necesariamente es así, sino que también apunto a ofrecer un criterio o parámetro independiente que, al tiempo que aspire a señalar los límites de la eficacia motivacional de cualquier sistema penal, sea capaz de evaluar tanto su justicia como su nivel de legitimidad. Según lo que diré, este criterio viene dado por lo que podríamos llamar un sistema de justicia penal de naturaleza consensual, cuyo comportamiento en cada una de las fases o sub-subsistemas que lo componen vendría a estar legitimado por el consentimiento de sus destinatarios.

Dos serán las hipótesis principales que me acompañarán en este recorrido. La primera apunta a destacar, siguiendo a John Simmons (2001), la necesidad de diferenciar entre la cuestión de la justicia de un arreglo institucional 
y la cuestión de su legitimidad (cfr. infra, sec. I). Como sabemos, la literatura reciente en torno a la justificación del castigo ofrece al menos dos claros exponentes de lo que implica apelar al consentimiento. Uno de ellos es la teoría consensual de la pena desarrollada por C. S. Nino, fundada en una noción efectiva de consentimiento, aunque de tintes claramente estipulativos ${ }^{1}$. El otro exponente vendría representado por la teoría de C. Finkelstein, fundada sobre una noción de consentimiento hipotético de tintes claramente rawlsianos (cfr. infra, sec. II, punto C). Pues bien, mi hipótesis es que, si trabajamos con la doble distinción formulada por Simmons, ello permitiría desarrollar una teoría consensual más comprehensiva, esto es: una teoría que sea capaz de explicar en qué instancias específicas cada noción de consentimiento estaría llamada a desempeñar su papel normativo más característico. Aunque el consentimiento hipotético, según argüiré, puede ser útil para determinar la justicia (o, en terminología de Simmons, la justificación) de un sistema penal, el consentimiento efectivo es el único que puede determinar su legitimidad (cfr. infra, sec. II)². Por su parte, la segunda hipótesis está relacionada con aquello que explicaría la fuerza normativa del consentimiento. En resumidas cuentas, lo que diré es

1 Dice Nino en concreto: «La falta de una expresión lingüística para denotar el tipo de actitud subjetiva que deseo describir y mi convencimiento de que lo que debe darse en el caso de los contratos para que haya lo que llamamos 'consentimiento', es esa actitud subjetiva, me han inducido a usar la palabra con el significado estipulativo que aquí se expone. Con este significado, es impropio decir, por ejemplo, que una persona 'prestó su consentimiento a realizar cierta acción', puesto que esto da la idea de que hubo una especie de compromiso previo a la ejecución de la acción. Habría que decir que la persona realizó la acción 'consensualmente', así como uno dice que alguien ejecutó una acción 'intencionalmente'. En definitiva, 'consentir' se emplea aquí como sinónimo aproximado de 'ejecutar o generar libre y conscientemente (un acto o un estado de cosas)'» (1980, p. 228).

2 En este punto sigo a Pereda, quien diferencia entre el consentimiento efectivo, el consentimiento hipotético y los consentimientos derivados. Sobre el primero de ellos, ofrece la siguiente definición: «P da a Q su consentimiento efectivo sobre $\mathrm{X}$ si, y sólo si, a) $\mathrm{P}$ expresa fácticamente a $\mathrm{Q}$ su aceptación de $\mathrm{X}$ en un tiempo t1 siendo $\mathrm{X}$ una acción particular o una clase de acciones claramente delimitada, b) X sucede en $\mathrm{t} 1$, y c) $\mathrm{P}$ expresa $\mathrm{Q}$ 'a título personal', esto es, como agente individual» (ibid., p. 103). En cuanto a qué significan los 'consentimientos derivados' y el 'consentimiento hipotético', Pereda escribe lo siguiente: «Mientras que las definiciones de los consentimientos derivados comparten con la definición del consentimiento efectivo la expresión 'P da a $\mathrm{Q}$ su consentimiento...', en la definición del consentimiento hipotético se dice 'P da según Q su consentimiento...'; de esta manera, quien o quienes reciben el consentimiento, en el consentimiento efectivo y en los consentimientos derivados, poseen el estatuto de una segunda persona que comprende un discurso; en cambio, quien o quienes 'reciben' el consentimiento en el consentimiento hipotético poseen el estatuto de una tercera persona que interpreta, a la vez, discursos y maneras de actuar» (2004, pp. 105-106). 
que en tanto el consentimiento se conciba como un acto comunicativo que sirva para alterar las relaciones normativas existentes entre dos partes, $\mathbf{P}$ y $\mathbf{Q}$ (cfr. Kleinig 2010, p. 5), de manera moralmente justificada, no tendremos más remedio que explicar su fuerza normativa apelando a la idea de «razones personales» para actuar. Estas razones, a veces también llamadas «razones agencialmente relativas», por oposición a las «razones impersonales» 0 «agencialmente neutrales», son las únicas que permitirían entender el valor expresivo del consentimiento en algunos contextos justificatorios (cfr. infra, sec. III).

El trabajo se divide en tres partes. En la sec. I, presento una serie de postulados relativos a la conexión que cabría trazar entre los sistemas penales y las precondiciones de nuestras democracias. En la sec. II, expongo los lineamientos centrales de lo que sería un modelo consensual de los sistemas penales, diseñado tanto para explicar su eficacia motivacional como para evaluar su funcionamiento desde el punto de vista moral. Y en la sec. III, finalmente, intento desentrañar cuál es la relevancia práctica o evaluativa de contar con un modelo semejante, especialmente cuando se trata de velar por la vigencia de nuestros sistemas democráticos de gobierno.

\section{DeMOCRACIA Y SISTEMA PENAL: DE PRECONDICIONES Y POSTULADOS}

«¿Cuál es la relación entre un sistema democrático de gobierno y el contenido del derecho penal?», pregunta Nino en «Derecho penal y democracia» (2013, p. 99). El interrogante, por cierto, abre un campo de reflexión sumamente amplio, el cual abarca múltiples frentes. Algunos de ellos son los siguientes: ¿existe un ámbito de derechos fundamentales que debería gozar de protección penal independientemente de lo que decida un proceso democrático? Si existe, ¿qué derechos deberían estar allí contemplados? ¿Existe alguna diferencia entre la cuestión relativa al tipo de derechos que merecerían una protección penal y la relativa al tipo de protección penal que debería ser provista para ellos? ¿No tiene la deliberación democrática mucho más sentido cuando se la concibe en relación a la segunda cuestión y no, en cambio, en relación a la primera? Por otro lado, suponiendo que éste sea efectivamente el caso, chasta dónde debe llegar la democracia? Un sistema de justicia penal, como sabemos, abarca mucho más que el contenido de su legislación y las vías por las que ésta se produce. Sólo por decir lo obvio, también abarca los modos en que ella se aplica: autoridades policiales, jueces, fiscales, procedimientos y recursos de distinta naturaleza componen, entre otras, algunas de las instancias que intervienen entre el momento en que 
se produce un delito y el momento en que se decide la condena o absolución de un acusado, si lo hubiera. Siendo entonces así, ¿cómo ha de concebirse la participación ciudadana a lo largo de todo este proceso? Y, lo que es más importante todavía, ¿cuál es el rol que el consentimiento individual o colectivo desempeña en cada una de estas instancias?

Con el objetivo de responder algunas de estas inquietudes y despejar desde el inicio el panorama conceptual, en esta sección daré por descontada la validez de una serie postulados o presupuestos, con independencia de los cuestionamientos que algunos de ellos podrían llegar a suscitar. A mi humilde entender, la mayor parte de ellos capturan ideas bastante plausibles y a favor de las cuales -según se apreciará- han argumentado grandes teóricos del derecho y la filosofía política. Otros, en cambio, capturan ideas cuyo carácter sería más bien intuitivo. Por razones de espacio, aquí sólo puedo pedirle al lector que asuma la validez de los mismos en el orden en el que están expuestos. De todas formas, puesto que hay algunos de ellos que han sido criticados con muy buenos fundamentos, hacia el final de esta numeración introduciré una pequeña reflexión tendiente a reforzar mi postura. Sin más preámbulos, los postulados son los siguientes:

1. La democracia (deliberativa) es el mejor procedimiento disponible -aún si altamente imperfecto y difícilmente infalible (Nino 2013, p. 107)- para acceder a la verdad moral relativa a cómo hemos de vivir colectivamente en sociedad, en la medida en que dicho procedimiento suponga la participación efectiva en la toma de decisiones de todos los posibles afectados (Nino 1996).

2. No hay democracia (deliberativa) posible si no se garantizan una serie de precondiciones o prerrequisitos, como el derecho universal al voto, el derecho a ciertas formas de propiedad, a la integridad física, a la libertad de expresión o a contar con un proceso justo (cfr. Nino 1996; Martí 2008). En efecto, una democracia plena supone la posibilidad de que cada ciudadano participe de manera directa o indirecta en las decisiones de los tres poderes del Estado. En la medida en que estas precondiciones garantizan dicha participación, ellas deberían quedar al resguardo del mismo procedimiento democrático de toma de decisiones ${ }^{3}$.

3 Sobre la paradoja que encierra este postulado o presupuesto, véase nuevamente Martí 2008 y Nino 1996, especialmente pp. 136-141. Para comprender en qué consiste la señalada paradoja, lo primero que debe advertirse es el carácter abierto que encierran los derechos derivados de 
3. Sin un sistema de justicia penal que proteja integralmente estos derechos, no habrá posibilidad de construir una democracia sólida y duradera.

4. Aunque muchos de estos derechos podrían satisfacerse prescindiendo de un sistema de justicia penal, dicho sistema constituye la garantía de ultima ratio a la que pueden apelar los ciudadanos en una democracia constitucional.

5. Sean A y B dos regímenes democráticos y constitucionales. Las constituciones respectivas de A y B consagran los mismos derechos y garantías individuales. Sin embargo, mientras el régimen A cuenta con una legislación penal y un sistema de justicia que protege estos derechos y garantías, sancionando su violación, no sucede lo mismo con B. Aunque en el régimen constitucional B nunca nadie ose violar los derechos y garantías allí consagrados, B será menos democrático que A, por constatarse en dicho régimen un nivel de protección menor para las precondiciones de la democracia (cfr. Pettit 2012; Estlund 2011, cap. 8).

6. Un régimen democrático y constitucional provisto de un sistema de justicia penal altamente inefectivo resulta en la práctica equiparable a un régimen democrático y constitucional que carezca de cualquier forma de sistema penal.

7. Un sistema de justicia penal constituye un conjunto de sub-sistemas interrelacionados que gozan de autonomía relativa, «como los atinentes a legislar, ejercer funciones policiales, procesar judicialmente, determinar penas, la libertad restringida, la reclusión, etc.» (Braithwaite y Pettit 2015, p. 34; asimismo, véase Luhmann 2005, p. 93 y sigs.; y Guibourg 2009).

8. Ningún sistema de justicia penal resulta defendible en ausencia de leyes que garanticen o protejan las precondiciones de la democra-

estos prerrequisitos, algo que Nino reconoce explícitamente en La constitución de la democracia deliberativa (1996, p. 139). Esto significa que no hay nada que en principio pueda evitar que el conjunto de tales derechos se vaya incrementando a espaldas de los procesos democráticos de toma de decisiones, por ejemplo, mediante el ejercicio de la judicatura. Pues bien, mediando esta aclaración, la paradoja consiste, según Martí la define, «en que podemos tener un excelente y poderoso procedimiento de toma de decisiones democráticas que se aplique a un rango de decisiones muy reducido, o un pobre y poco fiable procedimiento que se aplique a un rango casi total de decisiones» (2008, p. 311). De acuerdo a Martí, la paradoja sería irresoluble. 
cia, por más que dichas leyes sean palmariamente insuficientes para brindar dicha protección. Así, por lo pronto, si un sistema protege la propiedad privada pero no la libertad de expresión o la integridad física, no resultará justificable (sobre este punto, véase infra).

9. Habiendo múltiples maneras de brindar protección legal o penal a las precondiciones de la democracia, un sistema penal será mejor que otro en la medida en que alcance a proteger de manera coherente la mayor cantidad de precondiciones posibles.

10. A priori, no hay manera de evaluar la bondad de una ley penal tendiente a proteger una precondición de la democracia que no nos remita tanto al lugar que dicha ley ocupa en un sistema de justicia penal, como asimismo al lugar que tanto la una como el otro ocupan en relación a otras leyes y otros sistemas jurídicos y/o sociales.

11. Si el contenido y funcionamiento de un sistema de justicia penal condiciona la existencia de una democracia, la democracia también condiciona el contenido y funcionamiento de un sistema de justicia penal.

12. Para que un sistema de justicia penal garantice las precondiciones de una democracia no es necesario que el mismo sea democrático. Esto significa que puede existir un sistema de justicia penal que, sin ser democrático, aparezca mínimamente justificado. Sin embargo, para que un sistema de justicia penal sea legítimo, el mismo deberá ser democrático. Siguiendo a Simmons (2001), cabría distinguir entre la justificación y la legitimidad de un sistema de justicia penal. Un sistema de justicia penal justificado será, en lo que aquí respecta, un sistema que garantice las precondiciones de una democracia. Por su parte, un sistema de justicia penal legítimo será un sistema que tenga tanto un origen como un funcionamiento democrático.

13. La legitimidad de origen de un sistema de justicia penal no necesariamente garantiza la legitimidad de su funcionamiento, por razones similares a las que explican que la legitimidad de origen de un gobierno tampoco garantiza su legitimidad de ejercicio (López Hernández 1999, p. 156).

14. Tanto la legitimidad de origen como la legitimidad del funcionamiento de un sistema de justicia penal descansan en última instancia en la participación democrática de sus destinatarios. Sólo por tomar lo que sucede en terreno legislativo, a fin de que ello sea posible no sólo es necesario que los propios destinatarios del sistema penal se 
involucren en el dictado de sus leyes, sino también a la hora de garantizar la vigencia de su contenido.

15. Hay al menos dos factores que explican la vigencia de un sistema de justicia penal: por una parte, el grado de obediencia que susciten sus leyes; y, por la otra, la aplicación eficaz de las mismas en caso de que se verifique su incumplimiento.

16. La legitimidad democrática de todo sistema de justicia penal, tanto en su origen como en su funcionamiento, implica que en última instancia dicho sistema cuenta con el consentimiento de sus destinatarios.

Tal como se habrá notado, el postulado $\mathrm{n}^{\mathrm{o}} 12$ captura una de las dos hipótesis que guían a este trabajo, referida a la diferencia que existe entre la justicia y legitimidad de un arreglo institucional (cfr. supra). Si aquí no me he dispuesto a fundamentarla con el rigor del caso, ello se debe a que en general concuerdo con lo que manifiesta Simmons en su excelente artículo. De todas formas, no quisiera dejar pasar la oportunidad para expresar por qué esta distinción resulta útil a la hora de analizar ciertos planteos, vinculados por ejemplo a postulados como el $\mathrm{n}^{\circ} 2$, el $\mathrm{n}^{\circ} 13$ o el $\mathrm{n}^{\circ} 14$. En particular pienso en una crítica como la que Gargarella le dirige a L. Ferrajoli en «Mayorías democráticas y derecho penal» (2016, pp. 59-79). Allí sostiene que la idea de sustraer un ámbito de derechos fundamentales, como el derecho a la vida o a la libertad personal, de la voluntad de las mayorías, estableciendo un «territorio inviolable» (según Bobbio), un «coto vedado» (según Garzón Valdés) o una «esfera de lo indecidible» (según denominación del propio Ferrajoli), responde a una concepción falaz de la democracia, proclive a constatar en las mayorías una suerte de tendencia irrefrenable por despedazar los intereses de las minorías. A mi juicio, esta crítica resulta sumamente atinada en un aspecto específico: puesto que nadie puede evitar que un derecho entre circunstancialmente en colisión con otro derecho, y puesto que el mayor o menor peso que uno demuestre tener en relación al otro no puede estar exento de interpretaciones y demás consideraciones valorativas, no hay manera de inmunizar su protección de lo que de alguna manera dicte el proceso democrático. Ahora bien, si esto implicara negar de plano la posibilidad de definir cierto núcleo de derechos como merecedor de una protección especial y con independencia de lo que dicte el proceso democrático, allí creo que se comete un error difícilmente subsanable.

En este sentido, sospecho que la crítica de Gargarella corre el riesgo de ocultar qué dos órdenes de consideraciones parece generar en el ámbito del 
derecho penal la distinción trazada por Simmons: el referido, por un lado, al tipo de derechos que incondicionalmente merecerían una protección penal; y el referido, por el otro, al tipo de protección penal que debería ser provisto para ellos. A grandes rasgos, podría decirse que el primer orden de consideraciones está destinado a definir el área de conductas que ninguna sociedad debería dejar de considerar delictivas. Me refiero fundamentalmente a conductas como el asesinato, la violación, la agresión, el secuestro, el acoso, la extorsión, el allanamiento de morada, el robo y la estafa, justamente aquellas tipologías delictivas que vulneran lo que Braithwaite y Pettit denominan el dominio de un agente, por atentar contra su persona, su propiedad o su libertad (cfr. 2015, Cap. 4). En cambio, el segundo orden de consideraciones parecería destinado a hacer lo propio en relación a la modalidad penal aplicable a cada delito, tarea en la cual la deliberación democrática sería mucho más relevante. Por supuesto, nada de esto significa que la deliberación democrática no sea necesaria para configurar con el mayor detalle posible cada una de las tipologías delictivas mencionadas, tanto como para configurar otras nuevas. Sin embargo, a diferencia de lo que sostendría Gargarella, ella no parece central para juzgar la justicia sustantiva de un sistema penal. El dominio de una persona, tal como Braithwaite y Pettit entienden este concepto, parece ofrecer un criterio de justificación de los sistemas penales que es externo al procedimiento democrático de toma de decisiones, a la vez que condición de posibilidad del mismo. Ambos enfoques, pues, no serían en modo alguno incompatibles.

\section{CONSENTIMIENTO, MOTIVACIÓN Y SISTEMAS PENALES: UNA PROPUESTA EVALUATIVA}

Dados estos supuestos o postulados, analicemos ahora sí qué nos permite inferir $e l$ becho de que en una sociedad se constaten un determinado número de delitos acerca del comportamiento de un sistema penal y qué se sigue de todo ello desde el punto de vista moral. En otras palabras, ¿cuándo podría afirmarse que un sistema penal se halla íntegramente justificado? A continuación, expongo una serie de escenarios posibles con la intención de mostrar qué tendría para decir de cada uno de ellos un criterio consensual de justicia penal. En total, los escenarios ascienden a cuatro: 2.1, 2.2, 2.3 y 2.4. Cada uno de ellos, como veremos, le atribuye al sistema penal una serie de características muy generales, vinculadas a su nivel de acatamiento, a su grado de eficacia sancionatoria y motivacional o a la tipología de delitos contemplados en su 
legislación. Un modelo consensual, tal como aquí lo concibo, sería el único con la dotación especial para evaluar estas características de manera comprehensiva, a diferencia de lo que sucede con otros modelos consensuales o no consensuales tendientes a justificar el castigo penal. Al final de este recorrido (2.5), espero que logren apreciarse cuáles son las ventajas que exhibe este modelo cuando se lo compara con algunas de las alternativas en danza.

\subsection{La obediencia al sistema}

Comencemos imaginando un sistema penal de gran eficacia sancionatoria y en el que el grado de obediencia o acatamiento normativo de sus destinatarios también fuera muy elevado. ¿Qué nos diría esto, por lo pronto, acerca de la eficacia motivacional del mismo? Todo dependerá de los motivos o razones que impulsen a los destinatarios a obedecer. Si la mayoría de ellos estuvieran impulsados por el temor a la sanción que el sistema imparte en caso de desobediencia, la eficacia motivacional del sistema sería muy alta. Sin embargo, es probable que su legitimidad fuera muy reducida. ¿Por qué? Porque la legitimidad del funcionamiento de un sistema penal tiene que ver con el consentimiento de sus destinatarios y, en un escenario como el descripto, la obediencia movilizada por el temor a la sanción es compatible con la más firme voluntad de disentimiento. En cualquier caso, esto se parece a la situación de quien consiente bajo amenaza de coacción. ${ }^{4}$ Desde luego, en una sociedad regida por un sistema de justicia penal, habrá personas que obedezcan sus leyes sólo por temor a la sanción y otras que lo hagan convencidas de la justicia sustantiva que ellas encierran, de la competencia epistémica que reúne la autoridad que las ha dictado, simplemente por costumbre o por una razón personal más de tipo idiosincrásica. Podría decirse entonces que una sociedad en la que la mayoría de sus habitantes (o un número importante de ellos) obedecen las leyes penales por cualquiera de esta segunda clase de razones se acercaría bastante a una sociedad capaz de expresar cierta forma de consentimiento. Sea ésta, pues, la primera característica de un sistema de justicia penal de naturaleza consensual.

4 Expresado en las célebres palabras con que Hegel criticara la teoría penal de Feuerbach: «El derecho y la justicia deben sin embargo tener su lugar en la libertad y la voluntad y no en la falta de libertad a la que se dirige la amenaza. Con esta fundamentación de la pena se actúa como cuando se le muestra un palo a un perro, y el hombre, por su honor y su libertad, no debe ser tratado como un perro» (Principios de la filosofía del derecho, $\$ 99$ ). 


\subsection{La legitimidad del sistema}

Con todo, para que podamos estar en presencia de un sistema penal auténticamente legítimo, esto no basta. Por ejemplo, imaginemos que un sistema penal cuenta con un alto nivel de acatamiento normativo, pero cuyas leyes fueran sancionadas o aplicadas de espaldas a la ciudadanía. En este caso, puede que la eficacia del sistema se explique todavía por el consentimiento de sus destinatarios. Sin embargo, difícilmente esto explique la legitimidad del funcionamiento del sistema penal como un todo. Para que ello sea posible, lo que debe suceder es que sus destinatarios participen tanto de la creación, vigencia o reforma de sus leyes, como de la creación, vigencia o reforma de cada uno de los sub-sistemas que lo componen, involucrándose directa o indirectamente en su funcionamiento. Según quedara plasmado en los postulados precedentes, todo esto hace tanto a la legitimidad de origen como a la legitimidad de ejercicio de un sistema de justicia penal, dos aspectos que son de suma importancia cuando se trata de justificar la sanción penal que se le impone a un particular. Si éste no ha podido participar en ninguna de estas instancias legitimadoras, es probable que su sanción -por un acto delictivo que se presume cierto, desde luego- aparezca menos fundada que si hubiera podido hacerlo. Sea ésta, entonces, la segunda característica de un sistema de justicia penal de naturaleza consensual.

\subsection{La justicia del sistema}

Imaginemos ahora un sistema penal democrático que sancione los delitos contra la vida, pero no los delitos contra la propiedad. Más aún, supóngase que dicho sistema opere en soledad y que no existan disposiciones jurídicas de otra naturaleza tendientes a proteger la propiedad, como un sistema de justicia civil que ofrezca cierto tipo de compensaciones para quienes resulten damnificados. Si, en dicho sistema, el individuo $\mathbf{P}$ decidiera unilateralmente invadir o afectar la propiedad de $\mathbf{Q}$ y el único criterio evaluativo disponible fuera el de la legitimidad, caeríamos en el absurdo de admitir que, después de todo, dicha afectación resulta moralmente irreprochable, ya que $\mathbf{Q}$ ha participado de la creación y vigencia del propio sistema penal que apaña esa clase de conductas. Sin embargo, muy distinto es el caso si trabajamos al mismo tiempo con un criterio evaluativo independiente, anclado en una noción como la de consentimiento hipotético. ¿Cómo hemos de reconstruir esta noción? 
Una alternativa es hacerlo a la manera de John Rawls. Dicho grosso modo, un sistema penal estará justificado desde el punto de vista consensual si satisface los estándares mínimos que serían elegidos por un conjunto de individuos, situados en una suerte de posición original. Quien ha desarrollado con cierto detalle esta idea es ni más ni menos que Claire Finkelstein (2011). Razonablemente, ella parte de la idea rawlsiana de que «la sociedad es una empresa cooperativa para obtener ventajas comunes» (Rawls 1979, p. 18), cuya estructura institucional debería ser evaluada por cada individuo tomando como referencia los beneficios y perjuicios que se producirían en su ausencia. ¿Pero cuáles serían las instituciones básicas que todos elegirían si tuvieran que determinar de qué manera estarían mejor [be better off]? Por lo pronto, la representada por un sistema de justicia penal. Así resume Finkelstein su postura:

Aplicada a la institución del castigo, un enfoque contractualista racional sostiene que los miembros de la sociedad alcanzarían entre ellos un acuerdo amplio en relación a los rasgos generales de un sistema sancionatorio, basados en el hecho de que se considerarían a sí mismos como los beneficiarios del efecto disuasivo de ese sistema (2011, p. 318)

Ahora evaluemos esta aproximación a partir de los postulados introducidos en la sección anterior. Según allí sostuve, quienes comparten la convicción de que la democracia (deliberativa) es el mejor procedimiento disponible para acceder a la verdad moral relativa a cómo hemos de vivir colectivamente en sociedad (postulado 1), deben asimismo suponer que no hay democracia (deliberativa) posible si no se garantizan una serie de precondiciones o prerrequisitos, como el derecho universal al voto o a ciertas formas de propiedad (postulado 2). Dados estos dos postulados, también debe aceptarse que, sin

5 He criticado este enfoque, al igual que la teoría consensual de la pena de Nino, en PARMigiaNI, M., «Is It Impossible to Will to Be Punished? Outlining a Consensual Way Out of the Kantian Dilemma», Revista de Estudios Kantianos, vol. 2, núm. 1 (2017), pp. 60-88. De cualquier modo, a los efectos de la presente discusión, baste con decir que la razón principal por la cual ambos enfoques resultan insuficientes desde el punto de vista justificatorio se debe a que sólo le adjudican al consentimiento una esfera de acción muy reducida. Mientras el enfoque de Finkelstein sólo opera en el plano de la justicia de los sistemas penales, tal como aquí lo he definido, el enfoque de Nino sólo lo hace en el plano de su aplicación, es decir, cuando se trata de justificar la distribución del castigo sobre un infractor. No obstante, un intento por empezar a saldar esta deuda puede verse en Nino 2013. 
un sistema de justicia penal que garantice el respeto por estos derechos, será mucho más difícil asegurar un modo de vida auténticamente democrático (postulado 3). Pues bien, a diferencia de esta triple secuencia de postulados, resulta evidente que el objetivo básico presupuesto en la posición original, tal cual Finkelstein la reconstruye, consiste en garantizar el bienestar individual, no un modo de vida democrático. Sin embargo, a mi modo de ver, no hay ninguna necesidad de postular que los agentes que intervienen en ese contrato hipotético sólo se comportan como egoístas racionales. El propio Rawls, por caso, sostuvo que ellos son portadores de lo que llamó «dos facultades morales»: por una parte, «la capacidad de poseer un sentido de la justicia», y, por la otra, la de «poseer, revisar y perseguir racionalmente una concepción del bien» (2004, p. 43).

En cierto sentido, la asunción aquí realizada obedece a un patrón similar: en tanto los contratantes hipotéticos compartan la convicción de que la democracia es la mejor forma de gobierno y asuman que, prescindiendo de ciertos derechos, no habrá democracia posible, es altamente probable que ellos lleguen a la conclusión de que los sistemas de justicia penal son necesarios. Qué sistema penal hayan de aceptar, por cierto, dependerá de cuáles sean los derechos que asuman tener. Por eso, para volver al inicio de este punto, bien puede ser el caso que un sistema penal que reúna la segunda característica mencionada en el punto 2.2 sea un sistema consensual. Sin embargo, en tanto dicho sistema no sea capaz de garantizar aquella serie de derechos que los participantes de un contrato original establecerían como precondiciones de la democracia, faltará un elemento de vital importancia para que el mismo se considere íntegramente consensual. Valga ésta, pues, entonces, como la tercera característica que debe reunir un sistema penal de naturaleza consensual. ${ }^{6}$ Dado

6 El mismo planteo podría presentarse de manera alternativa en los términos de T. M. Scanlon. A partir de su idea de que la corrección o incorrección de una acción, medida o arreglo viene dada por «juicios acerca de lo que sería permitido por principios que nadie podría rechazar razonablemente» (cfr. 1998, p. 4), como base de un acuerdo para la regulación general de la conducta de todos, la justificación de un sistema penal vendría dada precisamente por el hecho de que nadie que sea consciente de las precondiciones que requiere una democracia podría rechazar razonablemente la presencia de un mecanismo como el representado por el sistema penal, condición indispensable de su aseguramiento. En la misma obra, Scanlon ofrece una justificación del castigo sustentada en el valor de elegir [the value of choice] (cfr. 1998, pp. 263 267), que no necesariamente coincide con mi propia reconstrucción de su postura. En cualquier caso, lo que importa en este contexto es entender cómo podría formularse una defensa alternativa del sistema penal que, siguiendo una línea scanloniana, descanse en la noción de consentimiento hipotético. 
que esta característica, en contraste con las dos anteriores, resulta mucho más polémica desde el punto de vista filosófico, es esperable que su constatación no sea en modo alguno una tarea sencilla ${ }^{7}$.

\subsection{La desobediencia al (y los límites motivacionales del) sistema}

Supongamos ahora que un sistema penal comparte estas dos características: la mayor parte de quienes acatan sus normas lo hacen tanto porque están convencidos de su justicia, digamos, como asimismo porque se han implicado, directa o indirectamente, en los procesos de su creación y/o aplicación. En dicho sistema, no obstante, se comprueba todavía un porcentaje determinado de la población que incurre en actividades delictivas. ¿Implicaría esta desobediencia de parte de un sector de la población que el sistema carece de eficacia motivacional y/o legitimidad? Si la desobediencia se apoyara en razones o motivos derivables de un funcionamiento deficiente del propio sistema, por supuesto que podría implicar ambas cosas. Sin embargo, podría suceder que los destinatarios de dicho sistema desobedecieran sus leyes, aunque impulsados por razones de otro calibre. ¿De qué naturaleza deberían ser estas razones para que el

7 En contra de la idea de que la noción de consentimiento hipotético sea una auténtica noción de consentimiento se han expresado autores como Nino (2013) y Simmons (2010). Nino escribe: «Aun cuando se ha interpretado que Rawls (1971) recurrió al consentimiento hipotético en su fundamentación de los dos principios sobre la justicia, mi interpretación preferida es que el consentimiento no es el fundamento último de estos principios, sino el hecho de que nuestro razonamiento moral incluye una regla de validación según la cual los principios correctos son aquellos que serían aceptados bajo condiciones ideales» (2013, p. 102). Simmons, por su parte, sostiene: «Decir que la sujeción a ciertas instituciones políticas habría sido acordada por contratantes perfectamente racionales y motivacionalmente sanos no parece más que un subterfugio para decir que esas instituciones son buenas, por gozar de virtudes que serían apreciadas y seleccionadas por unos electores ideales. Formular el punto de esa manera parece tener poco que ver con las premisas justificatorias basadas en lo que realmente hacen las personas de carne y hueso cuando acuerdan someterse a ciertas instituciones políticas. El problema del paternalismo (por caso) es un problema principalmente debido a la tensión básica que existe entre la apelación a lo que las personas realmente eligen y la apelación a lo que resulta mejor (o mejor para ellas). Las teorías de la obligación política basadas en el consentimiento hipotético no parecen por eso mismo calificar realmente como teorías consensuales» (2010, p. 314). Asimismo, véase Dworkin 1977, p. 151; y Klosko 2018, p. 354. Personalmente estoy dispuesto a respaldar estas críticas. Sin embargo, eso no podría ocultar el hecho de que las teorías contractualistas de inspiración kantiana, rawlsiana o scanloniana siguen recibiendo la denominación de teorías consensuales. Aquí no he hecho otra cosa que seguir a pie juntillas esta nomenclatura, con todo lo desafortunada que pueda parecer. 
sistema aún conserve eficacia motivacional y legitimidad? O, en otras palabras, ¿de qué naturaleza deberían ser las mismas para que el sistema de justicia penal todavía conserve la fisonomía de un sistema auténticamente consensual?

Según lo señalara al inicio, un sistema de justicia penal que fuera mayoritariamente obedecido sólo por el temor a la sanción que acarrearía su desobediencia podría ser con todo derecho un sistema penal eficaz, mas difícilmente sea un sistema penal consensual (cfr. Weber 1979, pp. 706-707). Para determinar, entonces, si se trata de un sistema penal de esta última clase, habría que indagar en los motivos o razones que impulsan a la sociedad a obedecer. Dejando de lado la costumbre, que resulta un tanto extraña a la idea de «razón», podríamos trazar una línea de demarcación entre dos grandes clases de razones: razones impersonales o agencialmente neutrales y razones personales o agencialmente relativas. Esta jerga terminológica, desde luego, ha sido responsable de sembrar una gran confusión filosófica, dificultando a veces en grado sumo la tarea de entender qué se discute cuando se emplea una u otra clasificación. De cualquier modo, en aras de la simplicidad, aquí voy a emplear estos conceptos conforme las siguientes definiciones:

- Razones impersonales (o agencialmente neutrales -R1) (cfr. Nagel 1986; Korsgaard 1996; Farrell 2004): aquellas razones que exigen/sugieren actuar de cierto modo con el fin de conservar/promover cierto bien/ valor imparcial o públicamente compartido. En este sentido, si V1 es el valor en juego (i.e. la paz social, una vida humana, etc.) que todos comparten y M1 es una medida, arreglo o acción tendiente a conservar/ promover dicho valor, $\mathbf{R} 1$ será una razón impersonal o agencialmente neutral para que un agente A1 (o un conjunto de agentes CA) apoye/n dicha medida o realice/n determinada/s acción/es en las circunstancias C, si y sólo si no hubiera otra alternativa tendiente a conservar/promover V1 que fuera superior a M1. Entre las razones impersonales, algunas poseen carácter concluyente o decisivo y otras poseen carácter meramente tentativo o provisional, dependiendo de qué otras razones impersonales o personales se comprueben en determinadas circunstancias. Así, por ejemplo, supongamos que una persona $(\mathbf{P})$ está siendo perseguida por una banda de secuestradores. Acuciada por las circunstancias, llama a mi puerta y pide auxilio $(\mathbf{C})$. Aunque $\mathbf{R} \mathbf{1}$ podría ser una razón impersonal para dejarla pasar (M1), debido a que no hay una alternativa superadora para proteger su vida (V1), perfectamente podría existir una razón $\mathbf{R} 2$ para negarle el ingreso (M2). Si, pongamos por caso, en mi casa habitara una persona cuya vida (V2) pudiera verse 
amenazada por la presencia de $\mathbf{P}, \mathbf{R} \mathbf{1}$ difícilmente ofrezca una razón concluyente o decisiva para optar por M1.

- Razones personales (o agencialmente relativas -R2) (cfr. Dancy 2006; Raz 2001; Scheffler 2006): aquellas razones que sugieren actuar de cierta manera con el fin de promover o conservar un valor vinculado a nuestra propia constitución agencial o identitaria, compuesta por nuestras preferencias, proyectos, lazos personales o concepciones particulares del bien. A diferencia de las razones impersonales, las razones personales no suelen presentar por sí mismas un carácter concluyente o decisivo. Sin embargo, acopladas a una razón impersonal, perfectamente pueden hacerlo. Así, sólo por seguir el ejemplo anterior, si yo decidiera negarle al extraño el ingreso a mi casa (M2) para proteger la vida de quien vive conmigo (V2), la justificación de mi conducta remitirá a dos clases de razones: por una parte, a una razón impersonal $\mathbf{R} 2$ derivada del valor V2; pero también, por la otra, a una razón personal $\mathbf{R} 3$ derivada del valor V3, que podríamos asociar con el valor especial que para mí tiene la vida de quien vive conmigo. En este caso, R3 presenta un carácter concluyente precisamente porque se asocia a la razón R2, que es de índole impersonal. Entre las razones personales, las hay de diferentes categorías: altruistas o egoístas; auto-interesadas o desinteresadas; autorreferentes o intersubjetivas; triviales o importantes; etc. Aquí, sin embargo, sólo voy a focalizarme en una categoría específica, integrada por lo que podríamos denominar razones meramente preferenciales, por un lado, y razones idiosincrásicas, por el otro. Mientras las primeras son, en cierto sentido, fácilmente modificables o maleables, por descansar en nuestras preferencias, las segundas responden a nuestros rasgos identitarios más profundos, lo que explica su mayor resistencia motivacional.

Con estas precisiones en mente, volvamos ahora al punto anterior. $\mathrm{Pa}$ recería a todas luces claro que un sistema penal con un bajo grado de eficacia sancionatoria y un índice más bien pobre de acatamiento normativo (a), esto es, un sistema motivacionalmente deficiente, tampoco podría resultar legítimo o consensual. En efecto, aunque el acatamiento normativo demuestra legitimidad o consentimiento sólo cuando es secundado por cierto tipo de razones (de carácter impersonal, por ejemplo), el significado de la desobediencia es más unívoco o transparente. En un sistema penal con estas características generalmente tendremos a suponer que la actividad delictiva responde a razones personales meramente preferenciales, ya que usualmente son este tipo de razones 
aquellas que el sistema penal no alcanza a desincentivar por medio de sus dispositivos sancionatorios.

Sin embargo, mientras existe una clase de delitos como el robo o la estafa que ninguna persona razonable cometería si la eficacia sancionatoria fuera absoluta, no es claro que esto suceda con otra clase de delitos, como algunos que exclusivamente afectan la vida, la integridad física o el honor. En tanto la primera clase de delitos responde por lo general a razones meramente preferenciales, la segunda clase puede obedecer a razones personales de carácter más bien idiosincrásico, las cuales pueden resultar sumamente difíciles de desterrar. Comparemos sin ir más lejos la acción de quien asesina a su pareja para heredar su fortuna con la acción de quien hace lo propio, pero para vengar una infidelidad. Resultaría muy difícil que en un sistema penal con una eficacia sancionatoria absoluta la primera razón fuera operativa. En tanto el sistema se muestre motivacionalmente eficaz, la razón tenderá a cancelarse. En cambio, es muy probable que no suceda lo mismo con aquellas razones de la segunda clase, las cuales pueden resultar mucho más resistentes al mecanismo motivacional representado por la sanción.

Por eso mismo, si ahora analizamos lo que sucede en aquellos sistemas penales dotados de un alto grado de eficacia sancionatoria y un elevado índice de acatamiento normativo (b), no resultará sorprendente encontrar que aquellos pocos delitos que se cometen, se cometan a pesar de (o a expensas de) la alta eficacia sancionatoria con que actúa el sistema. En Los límites de la responsabilidad penal, C. S. Nino sostuvo:

$\mathrm{El}$ agente consiente en asumir una responsabilidad penal cuando, o bien sabe que tal responsabilidad es una consecuencia necesaria de su actividad voluntaria, o, aunque crea que no es más que una posible consecuencia de su conducta, habría realizado la misma conducta si hubiera advertido que la responsabilidad penal era una consecuencia necesaria de ella (Nino 1980, p. 397).

Si ahora tomamos el recaudo de seguir a Nino y equiparar esta actitud con un consentimiento efectivo a la sanción (cfr. supra, nota $\mathrm{n}^{\circ} 2$ ), más allá de algunos problemas definicionales que todavía habría que resolver, tendremos que un sistema penal auténticamente consensual será un sistema que reúna por lo menos las siguientes dos condiciones:

1. Un elevado índice de acatamiento normativo que se explique por $\mathrm{ra}$ zones impersonales, no por razones personales, ya que las razones personales meramente preferenciales (o prudenciales) (cfr. McCormick 1990, p. 183), que son precisamente aquellas que explican la eficacia 
motivacional de los dispositivos sancionatorios, no son buenas indicadores del consentimiento individual (en otras palabras: son compatibles con el disentimiento).

2. Una desobediencia que, vaya o no seguida de su correspondiente sanción, se explique por razones personales de tipo idiosincrásicas, o no meramente preferenciales. Éstas son las razones no derivables de un funcionamiento deficiente del sistema. Además, ellas señalan, finalmente, la cuarta característica que habrá de reunir un sistema de justicia penal de naturaleza consensual ${ }^{8}$.

\subsection{Derivaciones}

Puesto que las razones personales de esta última categoría son las únicas que llevarían a un individuo a delinquir en cualquier escenario posible, ellas parecen demarcar los límites motivacionales a los que tarde o temprano deberá enfrentarse cualquier sistema de justicia penal. Reconocer este hecho, en

8 A propósito de la fórmula consensual planteada por Nino, la cual -según debe aclararse- no coincide con la que le otorga el sello más distintivo a su teoría consensual de la pena, podría suscitarse la objeción de que su naturaleza contrafáctica impide que se la tome con seriedad. Efectivamente, en clara contraposición a los enunciados contrafácticos de causalidad que se formulan en otros contextos (al respecto, véase en especial von Wright 1974, pp. 33-60), la fórmula citada no parece verificable por medio del método experimental. De cualquier modo, a los efectos de juzgar la validez del modelo consensual, esto es tan cierto como irrelevante. Como veremos a continuación (cfr. infra, sec. III), bien puede ser el caso que la cuarta característica que define a un sistema penal según el modelo consensual nunca se verifique en la práctica: entre otras razones, porque difícilmente ningún sistema penal alcance alguna vez a reunir el porcentaje máximo de eficacia sancionatoria que permitiría deducir de algunos delitos la operatividad de ciertas clases de razones personales. Sin embargo, para que el modelo consensual resulte plausible, basta tan sólo con que aquellos delitos que responden a motivaciones no meramente preferenciales sigan cometiéndose, dado que son estos delitos los que algunas personas -aunque no todas, desde luego- elegirían cometer en cualquier escenario posible de eficacia sancionatoria. En consecuencia, lo que cabría decir ante cierta tipología delictiva no es que ella revele necesariamente una clase determinada de motivación, compatible con la actitud consensual mentada por la fórmula de Nino; lo que cabría decir en su lugar es que, puesto que ciertos delitos son compatibles con una clase de motivación que no encuentra en la amenaza de sanción un disuasivo, el hecho de que ellos sigan evidenciándose en la práctica no puede constituir un firme indicador del funcionamiento más o menos eficaz de un sistema penal. Sin embargo, sí podría constituir un indicador relativamente fiable de su legitimidad, suponiendo -claro está- que dicho sistema consiga reunir en cierta medida las otras características ya mencionadas. Es fundamentalmente esto lo que el modelo consensual intenta exponer tomando distancia de otros enfoques justificatorios de la pena, pero especialmente del utilitarismo. 
realidad, no constituye ningún mérito particular del enfoque consensual. Sin embargo, al menos tiene la virtud de mostrarnos por qué algunas versiones algo toscas o esquemáticas del utilitarismo penal están condenadas a errar el blanco. En efecto, si las bondades de un sistema penal vienen definidas por su capacidad para reducir, prevenir o evitar el delito, como sostienen estas versiones (cfr. Duff 1986, p. 156; Braithwaite y Pettit 2015, p. 63), su mayor o menor éxito y justificación habrá de medirse teniendo en la mira la cantidad de delitos que se cometan. Pero esto no parece funcionar así ni siquiera en el terreno especulativo.

Para verlo de manera muy esquemática, pensemos en la existencia de dos sociedades, $\mathbf{X}_{\text {y }} \mathbf{Z}$, integradas por el mismo número de habitantes y gobernadas por las mismas leyes penales, las mismas reglas procesales y los mismos procedimientos democráticos de participación ciudadana. Es más, imaginemos que las instancias encargadas de perseguir y castigar el delito son exactamente idénticas en ambas sociedades, como asimismo lo es el grado de eficacia sancionatoria con que actúan sus respectivos sistemas penales, cercano al 100 $\%$. Siendo así, no hay motivos para pensar que los individuos de $\mathbf{X}$ tengan menores incentivos para delinquir que los individuos de $\mathbf{Z}$. Sin embargo, mientras en $\mathbf{X}$ se constata un determinado número de delitos, en $\mathbf{Z}$ se detecta un número superior. ¿Qué cabría decir al respecto?

Si el utilitarismo estuviera en lo cierto, esta diferencia sería inexplicable, dado que los sistemas penales de $\mathbf{X}_{\text {y }} \mathbf{Z}$ son, por hipótesis, idénticos. Pero en este lugar debe notarse la centralidad que adquieren los postulados 7 y 10 introducidos en la sección anterior. En particular el postulado 10 invoca la idea de que los sistemas penales no pueden concebirse con independencia del lugar que ocupan en relación a otros sistemas sociales: por ejemplo, un sistema cultural que viniera a fijar determinados parámetros de virtud u honor personal. Supongamos ahora que, de acuerdo a los patrones culturales imperantes en $\mathbf{X}$, la infidelidad amorosa no afectara en mayor medida el honor de quien la padece, mientras que, de acuerdo a los patrones imperantes en $\mathbf{Z}$, sucediera más bien todo lo contrario. ¿No resultaría lógico que en $\mathbf{Z}$ se cometan mayores crímenes pasionales que en $\mathbf{X}$, a pesar de que las penas fijadas para estos delitos y la eficacia con que se los persigue sean exactamente las mismas? A mi juicio, el modelo consensual tiene una manera de explicar esta diferencia para la cual el utilitarismo no parece hallar un lugar cómodo. Al reconocer la entidad de una clase particular de razones, a las que caractericé como no derivables del funcionamiento deficiente del sistema penal, el enfoque consensual es perfectamente capaz de equiparar ambos sistemas desde el punto de vista justifica- 
torio, debido a que ciertos tipos de delitos -en la jerga de Nino, precisamente los delitos consensuales- no responden a los mecanismos motivacionales presupuestos habitualmente por el utilitarismo.

Desde luego, esto no significa que la pena no desempeñe un rol preventivo, ni tampoco que dicho rol sea inseparable de ciertos mecanismos motivacionales. A mi juicio, ambas cuestiones resultan indiscutibles. Sin embargo, un modelo consensual de un sistema de justicia penal no tiene por qué negar nada de esto. Tal como aquí lo he concebido, sus pretensiones son otras. En realidad, el modelo ha sido diseñado ni más ni menos que para evaluar el funcionamiento de un sistema penal en lo que hace a su legitimidad y justicia, dos facetas que, por su propia constitución, el utilitarismo -según lo reconocen varios de sus críticos- se ve impedido de incorporar a su programa justificatorio (cfr. Duff 1986, pp. 164-172; Boonin 2008, pp. 37-84).

Ahora bien, debido precisamente a estas falencias es que se han propuesto otros modelos alternativos, como ciertas variantes del retribucionismo. Para algunas de ellas, tal el caso del expresivismo de Joel Feinberg (1970) o la teoría comunicativa del propio Duff, la función de la pena es la de portar un mensaje, ya sea a toda la sociedad o al mismo infractor al que se dirige, con total independencia del rol preventivo que contingentemente pueda cumplir. Sin ir más lejos, Duff piensa que la persuasión que procura el castigo, con el fin de que su destinatario «abrace los valores que lo condenan» y se arrepienta, constituye ni más ni menos que una auténtica empresa consensual, ya que en última instancia apela a la conciencia y comprensión del delincuente como una fuente necesaria y final de legitimación (cfr. Duff 2003, pp. 122ss.). No obstante, un sistema penal que ha de sancionar un delito que habría sido cometido de cualquier manera, incluso si el infractor hubiera contado con la certeza absoluta de que sería castigado, no parece tener demasiado para decirle a este infractor en calidad de reproche. Efectivamente, ¿qué podría intentar comunicarle si es el propio infractor quien ya ha aceptado su correspondiente sanción? Pero un modelo consensual como el aquí descripto, que tome nota de la cuarta característica antes citada, por lo menos se alza con el mérito de señalar los límites que ocasionalmente habrá de enfrentar una concepción comunicativa o expresiva de la pena. Desde luego, al igual que pasaba con el utilitarismo, esto no significa que la pena no pueda cumplir en general un rol comunicativo o expresivo apelando al consentimiento del delincuente como fuente última de legitimación. Sólo significa que, a veces, no podrá hacerlo, porque es el propio delincuente quien, mediante su propio acto delictivo, ya le habrá tomado la delantera en esta especie de carrera legitimadora. 


\section{EL CONSENTIMIENTO A LA SANCIÓN Y LOS LÍMITES DE LA DEMOCRACIA}

Quisiera finalizar el presente trabajo señalando cuál es la relevancia práctica o evaluativa de emprender una indagación semejante en torno a cómo debe interpretarse el desempeño motivacional de los sistemas penales y, consiguientemente, a qué vinculación tiene todo esto con los fundamentos y precondiciones de nuestras democracias (cfr. supra, sec. 1).

El consentimiento constituye una de las herramientas prácticas más importantes por medio de las cuales los seres humanos delinean y regulan sus interacciones cotidianas. En «The Moral Magic of Consent», H. Hurd le atribuyó una suerte de «magia moral», consistente en un poder para transformar «la moralidad de una conducta ajena», convirtiéndola en buena, justa o correcta cuando de otro modo sería mala, injusta o incorrecta (cfr. Hurd 1996, 123). Así, el consentimiento transformaría «una intrusión [trespass] en una invitación a cenar; una agresión [battery] en un apretón de manos; una invasión a la privacidad en un momento íntimo; o la apropiación comercial del nombre e imagen de una persona en una biografía» (ibid., 123). En otros casos, más que transformar un acto malo, injusto o incorrecto en un acto moralmente aceptable, el consentimiento simplemente concedería un permiso para que dicho acto sea ejecutado, sin que el mismo pierda su connotación moral negativa (cfr. ibid.). Por lo general, la noción de consentimiento es utilizada para validar arreglos o acciones entre personas. Tal cosa es lo que sucede de manera paradigmática en el ámbito del derecho privado vinculado a los contratos. Pero la noción de consentimiento también ha ocupado un lugar importante en el seno de la filosofía política, como bien lo sabemos al menos desde las obras de Thomas Hobbes y John Locke (cfr. Tuckness 2018). Aquí, según se habrá constatado, lo que he pretendido hacer es apropiarme de lo más característico de ambas tradiciones disciplinares, con el objetivo de indagar si el consentimiento puede rendir alguna utilidad en el ámbito penal.

Dos fueron los pasos clave en este recorrido. El primero vino dado por la distinción trazada por Simmons entre la justicia o justificación de una institución, arreglo o medida, y su legitimidad. El segundo, por la distinción entre razones personales e impersonales. Ambos pasos, operando coordinadamente, habilitan las siguientes reflexiones. En el plano de la justificación de los sistemas penales, permiten entender que la noción operativa es la noción de consentimiento hipotético. Allí, según se viera, el consentimiento que resulta relevante es precisamente el consentimiento que, en una suerte de 
posición original, un contratante ideal daría a una serie de precondiciones destinadas a garantizar la existencia de una democracia deliberativa, que es el valor impersonal o agencialmente neutral que -por hipótesis- todos comparten. Si un sistema de justicia penal es el mejor modo de proteger estas precondiciones, entonces dicho sistema sería elegido por todos los suscriptores de un contrato original. Sus razones, en cualquier caso, tenderán a ser impersonales?.

En cambio, no sucede lo mismo en el plano de la legitimidad vinculado al origen y funcionamiento de los sistemas penales, pues allí sí parecen ser más relevantes las razones personales -sin ser las únicas, desde luego-. Esto se aprecia de manera bastante nítida en lo que respecta a su faz puramente legislativa. Así, mientras sería un criterio sustantivo de justicia el que debe determinar los contenidos mínimos de una legislación penal, el único criterio en condiciones de legitimar los contenidos restantes que vendrían a complementar aquellos contenidos mínimos habrá de ser un criterio procedimental, basado en el consentimiento efectivo y personal de sus destinatarios, no en su consentimiento meramente hipotético. Nuestras leyes penales, pues, cuando se encargan de hacer bastante más que proteger aquellos bienes que condicionan nuestra agencia democrática, sólo pueden encontrar en el consentimiento de sus destinatarios la fuente final de legitimación. Y, mutatis mutandis, lo mismo

9 David Estlund tiene una comprensión radicalmente diferente de este punto. Según él, resulta central para la perspectiva contractualista «que las razones que motivan el rechazo de las propuestas en la situación de elección hipotética sean, en términos de Scanlon, 'razones personales'» (Estlund 2011, p. 335). En efecto, suponiendo que la cuestión primaria en el contractualismo rawlsiano sea la de arribar a una «concepción política de justicia razonable», las partes de la posición original no se preguntan esto; en su lugar, «se plantean (...) una cuestión secundaria: ‘Cuál de las propuestas disponibles maximizará mi canasta de bienes primarios sociales?»'» (ibid., p. 333). De manera análoga, suponiendo que la cuestión primaria en el contractualismo scanloniano sea la de determinar 'qué nos debemos unos a otros', los participantes de su contrato hipotético tampoco se plantean esto; en su lugar, se hacen la siguiente pregunta secundaria: «Encuentro aceptable esta propuesta a la luz de mis intereses (razonablemente ponderados) y en vistas de mi deseo de llegar a un acuerdo con otras personas análogamente motivadas?» (ibid., pp. 333-334). Aunque en términos generales estoy de acuerdo tanto con la reconstrucción que hace Estlund de las propuestas rawlsiana y scanloniana, como así también con las consecuencias que deriva de la misma para minar la analogía democracia-contractualismo, el tipo de contrato hipotético que yo he presentado está fundado sobre la presuposición de que todos los participantes comparten la convicción en el valor de la democracia (deliberativa). En términos del propio Estlund, este valor justamente constituiría una fuente de razones impersonales. Puesto que es la propia situación hipotética la que ha sido montada sobre la base de este valor, es lógico que las razones que de allí en más emanen de los contratantes hipotéticos no sean exclusivamente personales. 
cabría decir acerca del origen y funcionamiento del resto de los componentes que integran nuestros sistemas de justicia penal.

Ahora bien, tratándose de justificar moralmente la imposición de una pena sobre un particular, dicha fuente de legitimación parece perder asidero. Las razones son esencialmente dos. La primera es que resulta casi imposible hallar personas que consientan su propia pena. Existe, desde luego, una tipología de sistemas penales a los que podríamos denominar «triviales», por emplear penas que no alcanzan a ser lo suficientemente poderosas como para desincentivar la comisión de cierto tipo de delitos ${ }^{10}$. Estos sistemas, sin embargo, se parecen más a sistemas de justicia civil que a sistemas de justicia penal. Por ese motivo he decidido omitirlos en este análisis. En cualquier caso, la segunda razón que explica por qué el consentimiento que alguien pudiera expresar a la imposición de una pena está impedido de actuar como fuente de legitimación de la misma se debe a que, una vez que el sistema penal ha sido legitimado en su origen y funcionamiento por un destinatario cualquiera, el consentimiento a la propia pena que él alcance a expresar no parece dotar a la misma de nada que ésta ya no tuviera de antemano. ¿Por qué molestarnos entonces en la necesidad de indagar en torno a la naturaleza consensual de ciertos actos delictivos? ¿Y por qué molestarnos en la necesidad de recabar información sobre las razones que los impulsan?

La sugerencia que aquí he intentado respaldar es que, cuando un delito es cometido por razones personales de tipo idiosincrásicas, vinculadas a ciertos aspectos constitutivos de la identidad de una persona, dicho delito encerrará un componente expresivo que podría ser sumamente relevante a la hora de evaluar tanto la justicia como la legitimidad de un sistema penal. Como hemos visto, un sistema penal que gozara de una efectividad sancionatoria absoluta todavía sería compatible con un sistema penal cuyas leyes se desobedecieran. Tal sería el caso de lo que antes denominé un sistema penal consensual. Debido a que no consigue desincentivar cierto tipo de delitos, un sistema así se enfrentaría a los límites de su propia función motivacional. Desde luego, puesto que sistemas penales así no existen, daría la impresión de que nos estamos moviendo en el seno de una teoría irrisoria, carente de toda consecuencia práctica.

La impresión, no obstante, es errónea. Por supuesto que resulta improbable hallar sistemas penales con una eficacia sancionatoria del $100 \%$. Sin

10 Cfr. Parmigiani, M., «Is It Impossible...», op. cit. 
embargo, lo único que importa aquí es lo que esta simple posibilidad lógica nos habilita a inferir cuando llega el momento de juzgar la justicia y legitimidad de un sistema penal determinado. Lo que quiero decir es que incluso un sistema penal que no consiguiera disuadir aquel tipo de delitos que he llamado consensuales podría constituir, de todas formas, un sistema relativamente legítimo y relativamente justo. ¿Por qué legítimo? Básicamente porque existen transgresiones legales que son perfectamente compatibles con una manifestación del consentimiento a la sanción por parte de sus destinatarios. ¿Y por qué justo? En pocas palabras, porque si bien la justicia de un sistema penal tiene que ver con la capacidad que exhiba para garantizar las precondiciones de una democracia, esta capacidad tiene un límite, el cual viene determinado por la gama de razones personales que definen la identidad de cierta gente. Son estas razones las que no siempre pueden desincentivarse por la amenaza que la sanción representa. Por eso, en la medida en que estos delitos sigan produciéndose, ello no será necesariamente imputable a una falla del sistema penal. Todo dependerá, en cualquier caso, de cuántos delitos se cometan y cuántos queden impunes. Una tasa elevada de delitos sin resolver seguramente será un firme indicador de que el sistema, además de ineficaz, resulta injusto.

Muy distinto es el caso, en cambio, si los delitos que siguen aconteciendo responden a razones personales de corte meramente preferencial. Hablo en particular de delitos como el robo o la estafa, que son aquellos impulsados por la codicia o el simple afán de satisfacer una necesidad económica. En la medida en que estos delitos sigan evidenciándose, ello obedecerá a una falla del sistema penal, el cual se mostrará incapaz de proteger -por decir lo obvio- el derecho de propiedad de mucha gente, con todo lo que la protección de este y otros derechos presuntamente conlleva para el ejercicio de una voluntad autónoma y la plena incorporación de cada individuo a la vida democrática de una comunidad (cfr. Waldron 1988). Al mismo tiempo, es probable que un sistema penal así también experimente dificultades para alcanzar una dosis relativamente alta de legitimidad en lo que atañe al origen de sus leyes y al funcionamiento de los sub-sistemas que lo integran. En efecto, ¿podría suceder que un sistema que no garantizara plenamente el derecho de propiedad, por ejemplo, contara con el aval de sus destinatarios? Seguramente no. Pero lo que sí podría ocurrir es que la injusticia que lo caracteriza movilizara la participación de mucha gente, la que probablemente se implicaría de modo activo con el fin de promover los cambios que fueran necesarios. Sin embargo, en este punto debe notarse que un sistema penal que carece de estabilidad no representa en rigor un sistema penal legitimado, sino un sistema penal en proceso de legitimación. 
En una democracia deliberativa, el consentimiento (legitimador) se comporta como el último eslabón de la cadena.

Paradójicamente, un sistema penal con una efectividad del 100 \% sería un sistema penal dispuesto a garantizar las precondiciones de la democracia, pero también sería un sistema compatible con la desobediencia de algunos de sus miembros y/o destinatarios, quienes mediante sus actos delictivos se encargarían precisamente de minar aquellas precondiciones. La paradoja, no obstante, tiene una explicación bastante sencilla. Si la democracia (deliberativa) representa lo que muchos creen, a saber: la mejor forma de gobierno, esto se debe a que ella consigue como ninguna otra aproximarnos a decisiones imparciales sobre lo que resulta mejor para todos (cfr. Nino 2013, p. 108; Rosenkrantz 2004). Para que ella sea posible, ciertas garantías mínimas son indispensables, como la existencia de un sistema penal relativamente eficaz. Sin embargo, en un punto, no hay diseño institucional, por perfecto que sea, que alcance a lograr su cometido, comoquiera se defina, prescindiendo del firme compromiso de buena parte de su ciudadanía. Una explicación bastante plausible de dónde descansa la verdadera magia moral del consentimiento tiene que ver, por cierto, con las razones personales que nos impulsan a actuar. Sin ellas, el valor del consentimiento sería indescifrable. Son ellas, además, las que muchas veces nos instan a participar de los procesos democráticos de toma de decisiones. Lo curioso es que también sean estas razones las que frecuentemente amenacen la salud de la vida democrática. Si lo dicho hasta aquí ha podido valer como una reflexión general en torno a las condiciones de justicia y legitimidad de nuestros sistemas penales, espero que esto último pueda contar como un recordatorio de las fragilidades y limitaciones siempre latentes que acechan a nuestras democracias.

\section{BiBLIOGRAFÍA}

Braithwaite, J. y Pettit, P., Not fust Deserts: A Republican Theory of Criminal Fustice, Oxford, Clarendon Press, 1990 (citado por la traducción castellana: No sólo su merecido, Siglo XXI Editores, Buenos Aires, 2015).

Boonin, D., The Problem of Punishment, Cambridge University Press, Cambridge, 2008.

DANCY, J., «Enticing Reasons», en R. Jay Wallace, P. Pettit, S. Scheffler y M. Smith (eds.), Reason and Value. Themes from the Moral Philosophy of Joseph Raz, Clarendon Press, Oxford, 2006, pp. 91-118.

Duff, A., Trials and Punishments, Cambridge University Press, Cambridge, 1986. 
- Punishment, Communication and Community, Oxford University Press, New York, 2003.

Dworkin, R., Taking Rights Seriously, Harvard University Press, Cambridge (Massachusetts), 1977.

Estlund, D., La autoridad democrática, Siglo XXI Editores, Buenos Aires, 2011.

FARrell, M.D., «Autonomía y consecuencias», en H. Hongju Koh y R. C. Slye (compiladores), Democracia Deliberativa y Derechos Humanos, Gedisa Editorial, Barcelona, 2004, pp. 79-88.

FeInBerg, J., «The Expressive Function of Punishment», en J. Feinberg, Doing and Deserving, Princeton University Press, New Jersey, 1970, pp. 95-118.

FinkelsteIn, C., «Punishment as Contract», Obio State Fournal of Criminal Law, vol. 8 (2011), 318-340.

Gargarella, R., Castigar al prójimo. Por una refundación democrática del derecho penal, Siglo XXI Editores, Buenos Aires, 2016.

Guibourg, R., «Autonomía», Academia. Revista sobre la enseñanza del Derecho, año 7, $\mathrm{n}^{\mathrm{o}} 13$ (2009) pp. 207-211.

Hegel, G.W.F., Principios de la filosofía del derecho, Editorial Sudamericana, Buenos Aires, 2012.

Hurd, H., «The Moral Magic of Consent», Legal Theory, vol. 2, nº 2 (junio, 1996), pp. 121-145.

KleINIG, J., «The Nature of Consent», en Miller, F. \& Wertheimer, A. (Eds.), The Ethics of Consent, Oxford University Press, Oxford, 2010, pp. 3-24.

KLosko, G., «Consent Theory of Political Obligation», en A. Müller y P. Schaber (Editores), The Routledge Handbook of the Ethics of Consent, Routledge, Londres y New York, 2018, pp. 348-358.

KorsgaARD, Ch., «The Reasons We Can Share: An Attack on the Distinction between Agent-Relative and Agent-Neutral Values», en C. Korsgaard, Creating the Kingdom of Ends, Cambridge University Press, Cambridge, 1996, pp. 275-310.

López HERNÁNDEZ, J., «El concepto de legitimidad en perspectiva histórica», Cuadernos Electrónicos de Filosofía del Derecho, nº 18 (1999), pp. 154-166.

Luhmann, N., El derecho de la sociedad, Ciudad de México, Herder, 2005.

MARTí, J.L., «Un callejón sin salida. La paradoja de las precondiciones (de la democracia deliberativa) en Carlos S. Nino», en M. Alegre, R. Gargarella y C. F. Rosenkrantz (Coordinadores), Homenaje a Carlos S. Nino, La Ley, Buenos Aires, 2008, pp. 307-324.

Nagel, Th., The Possibility of Altruism, Oxford University Press, Oxford, 1970.

Nino, C.S, Los limites de la responsabilidad penal, Astrea, Buenos Aires, 1980.

- The Constitution of Deliberative Democracy, Yale University Press, New Haven, 1996.

- «Derecho penal y democracia», en C. S. Nino, Una teoría de la justicia para la democracia, Siglo XXI Editores, Buenos Aires, 2013, pp. 99-112.

Petrit, P., On the People's Terms. A Republican Theory and Model of Democracy, Cambridge University Press, Cambridge, 2012. 
PEREDA, C., «Lógica del consentimiento», en León Olivé (comp.), Ética y diversidad cultural, Fondo de Cultura Económica, Ciudad de México, 2004.

Rawls, J., A Theory of Fustice, Harvard University Press, Cambridge (Massachusetts), 1971 (también citado por la traducción castellana: Teoría de la fusticia, Fondo de Cultura Económica, Ciudad de México, 1979).

- La justicia como equidad, Buenos Aires, Paidós, 2004.

Raz, J., Value, Respect, and Attachment, Cambridge University Press, Cambridge, 2001.

Rosenkrantz, C., «La teoría epistémica de la democracia revisitada», en H. Hongju Koh y R. C. Slye (comps.), Democracia Deliberativa y Derechos Humanos, Gedisa Editorial, Barcelona, 2004, pp. 279-292.

Scanlon, T., What We Owe to Each Other, Harvard University Press, Cambridge (Massachusetts), 1998.

SCHEFFlER, S., «Projects, Relationships, and Reasons», en R. Jay Wallace, P. Pettit, S. Scheffler y M. Smith (eds.), Reason and Value. Themes from the Moral Philosophy of Foseph Raz, Clarendon Press, Oxford, 2006, pp. 247-269.

SimmONS, J., «Justification and Legitimacy», en A. J. Simmons, fustification and Legitimacy. Essays on Rights and Obligations, Cambridge University Press, Cambridge, 2001, pp. 122-157.

- «Political Obligation and Consent», en Miller, F. \& Wertheimer, A. (eds.), The Ethics of Consent, Oxford University Press, Oxford, 2010, pp. 305-328.

Tuckness, A., «Historical Perspectives in Political Philosophy», en A. Müller y P. Schaber (eds.), The Routledge Handbook of the Ethics of Consent, Routledge, Londres y New York, 2018, pp. 337-347.

Von Wright, G.H., Causality and Determinism, Columbia University Press, New York y Londres, 1974.

Waldron, J., The Right to Private Property, Clarendon Press, Oxford, 1988.

Weber, M., Economía y sociedad. Esbozo de sociología comprensiva, $2^{\mathrm{a}}$ ed., Fondo de Cultura Económica, México, 1979 (1ª ed. alemana 1922).

WoOD, D., «Retribution, Crime Reduction and the Justification of Punishment», Oxford Journal of Legal Studies, vol. 22, n 2 (2002), pp. 301-321. 